\title{
Micro-synchrophasor based special protection scheme for distribution system automation in a smart city
}

\author{
Deepa S. Kumar ${ }^{1,2^{*}}$ (D), Savier J.S. ${ }^{1}$ and Biju S. S. ${ }^{3}$
}

\begin{abstract}
Introduction: Aspects of power system protection which contributes to mal-operations and blackouts can be improved by supervision of system behavior and response based analysis rather than condition-based or event-based analysis using wide area measurements based on synchrophasor technology. The paper explores the application of micro-Phasor Measurement Unit for time synchronized real-time distribution network monitoring and agile decision support schemes for system prognosis and control.

Case description: The scheme is proposed as part of a project on "Power System Voltage Stability Analysis using synchrophasors in Distribution System of Kerala Grid" at Kerala State Electricity Board Ltd. An actual grid occurrence during the severe tropical cyclone Ockhi, is considered as the base case which motivated the work.

Discussion and evaluation: A voltage stability index (VSI) based special protection scheme (SPS) for radial distribution network at a proposed smart city is presented in the present study. The proposed special protection scheme on actual implementation can use data from proposed local micro-Phasor Measurement Unit. The PMU is proposed to be placed at one of the key nodes of the distribution system network in the city.

Conclusion: The VSI is derived using local phasor values and is used to initiate a Special Protection Scheme for N-1 contingency at the key node, so as to ensure availability of the most essential feeder which provides supply to a hospital campus housing several health institutes of prime importance. The voltage stability index derived is tested and SPS is validated using real-time grid data.
\end{abstract}

Keywords: Micro-phasor measurement unit, Power system protection, Voltage stability, Power system stability, Power distribution, Smart grids

\section{Introduction}

Driven by large scale growth and penetration of distributed energy resources (DER), distribution networks face an unprecedented evolution and the rising of prosumers increases energy management and control challenges in dynamic, complex distribution networks. The advent of $\mu$-PMUs in distribution system has been proven as a tangible solution for acquiring high resolution measurement data. Development of novel monitoring systems

\footnotetext{
*Correspondence: deepa.kumar@powergridindia.com

'Dept of Electrical Engineering, College of Engineering, Trivandrum, Kerala, India

${ }^{2}$ 400/220kV Substation, Powergrid Corporation of India Ltd., Trivandrum, Kerala, India

Full list of author information is available at the end of the article
}

to achieve situational awareness at distribution-level is the need of the hour to support distribution system operators in making proactive decisions during system disturbances. The imminent utilization of synchrophasor data in the distribution network is to be supported with cutting-edge research to bring out the potential applications to the fullest use by power system community. In India, the PMU deployment has been covered only in transmission system while the applications of $\mu$-PMU in distribution system is yet to be exploited completely and is yet to achieve attention from utilities for practical implementation. Kerala State Electricity Board Ltd. (KSEBL) is the only stateowned integral utility in power sector of Kerala with a consumer base of nearly 124 lakhs, out of which nearly 
5000 are high tension and remaining all low tension consumers. Thiruvananthapuram, the capital city of Kerala tops among the 30 new cities recently added to Government of India Smart Cities Mission. The vision for a smart city stresses upon a reliable, safe, quality 24/7 electricity supply to be established with a smart distribution grid. As part of this effort, in order to ensure reliable, robust and uninterrupted power supply at institutes of importance in the proposed smart city, the deployment of microPhasor Measurement Unit ( $\mu$-PMU) is explored as part of distribution system automation.

In the proposed smart city, Paruthippara substation, one of the key nodes in the power distribution network of the capital was considered under this study as a pilot initiative. 110 kV Paruthippara substation (SS) under Thiruvananthapuram Project Management Unit is feeding $110 \mathrm{kV}$ Medical College SS and other important $66 \mathrm{kV}$ as well as $11 \mathrm{kV}$ loads. The outgoing $110 \mathrm{kV}$ Medical College feeders feed Government Medical College (MC) campus, the oldest and most prestigious medical college in Kerala state. Medical College campus houses several institutions of importance including Regional Cancer Centre, Thiruvananthapuram, Dental College, Sree Chitra Thirunal Institute of Medical Sciences and Technology, Regional Institute of Ophthalmology (RIO), Government College of Nursing, College of Pharmaceutical Sciences, Priyadarshini Institute of Paramedical Sciences and Sree Avittom Thirunal Hospital for Women and Children.

This paper devises a special protection scheme based on synchrophasors for the emanating distribution system from Paruthippara SS. This scheme can serve as an integral part of the Distribution Management System under implementation by KSEBL in Thiruvananthapuram, the proposed smart city. Keeping in view an actual grid occurrence during Ockhi, the severe tropical cyclone that devastated various parts of SriLanka and southern India from 29 November to 6 December 2017 as the base case, a special protection scheme is derived in the present study to enhance the voltage stability of distribution system. The scheme is proposed as part of a project on "Power System Voltage Stability Analysis using synchrophasors in Distribution System of Kerala Grid" at Kerala State Electricity Board Ltd. Special protection schemes (SPS) are designed for tackling rare contingencies, when the consequences of a particular operating point at a particular system state is beyond the capability of conventional protection scheme. SPS are tailor-made schemes with a predetermined control action sequence and operates less frequently. The SPS formulated here is a synchrophasor based adaptive scheme that supports local decisions of distribution system operator at Paruthippara SS, for maintaining the system voltage stability. The paper is structured as follows: Section 2 presents a background review on the evolving synchrophasor technology applications and $\mu$-PMU deployment in distribution system. Section 3 describes the base case which served as motivation for deriving the special protection scheme. Section 4 discusses the methodology for developing the SPS application. Section 5 talks about the simulations done using actual grid data and the validation of the method suggested using results obtained. Section 6 concludes the paper and presents future scope of research in line with the work done.

\section{$2 \quad \boldsymbol{\mu}$-PMU for smart distribution system}

The effective deployment of micro Phasor Measurement Units ( $\mu$-PMU) [1] for real-time wide area monitoring and control of large and renewable rich complex power system thus enhancing system operational efficiency is being explored by utilities worldwide. For PMU deployment in Indian power system, a hierarchical architecture is established for routing and updating GPS time synchronized information at the respective Load Dispatch Centre, via high-speed wide- band communication network at rates up to 60 cycles per second [2,3]. Dynamic response of the system is revealed by the high-resolution time synchronized PMU data. This helps in designing adaptive wide area monitoring, protection and control (WAMPAC) applications for visualization real-time system behavior and improving system stability as well as reliability [4-6]. The state of art synchrophasor technology is a stepping stone towards a smart, intelligent transmission or distribution system with highest operation efficiency. A broad spectrum of potential applications of synchrophasors in distribution systems have been acknowledged in [7-10]. The evolution of low cost PMU designs for monitoring and islanding microgrids considering growing DG integration is pointed out in [11]. Deployment of PMUs at distribution level in several Nordic universities for development of various WAMPAC applications is discussed in [12]. The Indian institutional experience and efforts by Indian utilities to integrate PMUs and its applications for transmission and distribution grid operation are brought out in [13]. While WAMPAC applications in transmission system extends to intricate inter area oscillation identification, the greatest contribution of $\mu$-PMUs to support distribution system automation is the time synchronized phase magnitude and angle measurements i.e. the time series. The typical $\mu$-PMU deployment structure is shown in Fig. 1.

$\mu$-PMU is connected to single phase or three phase distribution circuits for continuous sampling of GPS time synchronized voltage and current phasors at a rate of two readings in a cycle which is $1.08 \times 10^{5}$ times the reporting rate of a typical smart meter. $\mu$-PMU is utilized for descriptive analytics in grid management and supervision. The high-fidelity $\mu$-PMU data is a significant leap towards toward preemptive analytics. An event of utilizing time synchronized $\mu$-PMU measurements with high temporal 


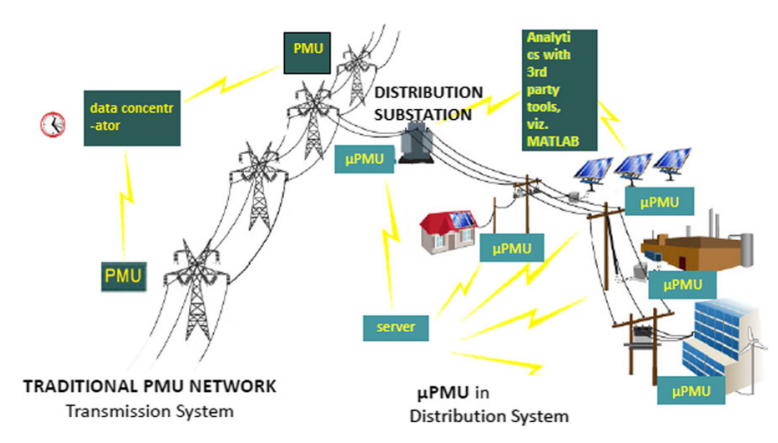

Fig. 1 PMU deployment structure [14]

resolution in root-cause analysis of voltage sags is shown in Fig. 2.

Studies by Lawrence Berkeley National Laboratory (LBNL) on high-precision $\mu$-PMUs being developed by Power Standards Lab is presented in $[14,16]$ where LBNL focuses on synchrophasor data for control and diagnostic applications in distribution systems. The capabilities of synchrophasor in distribution grid along with challenges and lessons learned are discussed in [16, 17]. Synchrophasor data from $\mu$-PMU deployed at multiple campus locations as well as utilities are used to analyze the planning and operation of supporting distribution system and DG control which includes generation and storage. Diagnostic as well as control applications are delineated in [17]. Diagnostic applications aid the power system planners and operators to comprehend the present or past state of the distribution system better, thus providing enhanced decision making capability on equipment maintenance, interconnection of resources or network rearrangement. Control applications focus on real-time decisions / specific actions in response to a challenging power system condition and it directly alters power system operating point through reconfiguration of circuit topology or demand response variations [18]. A comprehensive review on a wide range of applications intended for smart distribution feeders, including innovative developments in transmission system synchrophasor applications which

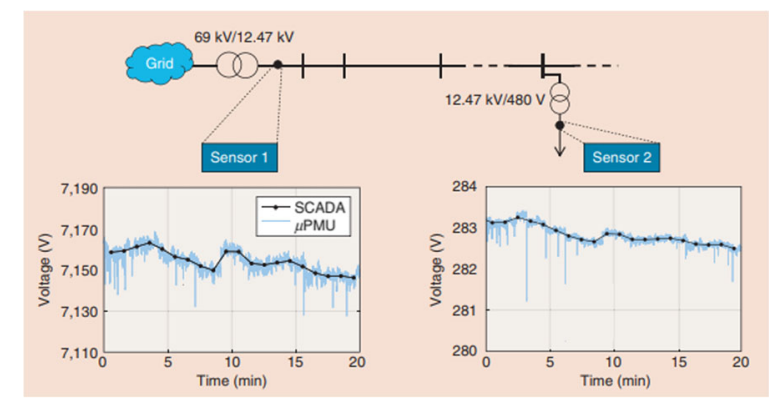

Fig. $2 \mu$-PMU v/s standard SCADA [15] can prove equally good for distribution systems, is presented in [19]. A grid study is presented in [20] which is a significant push towards realization of the vast possibilities of $\mu$-PMU measurement by depicting the application in a real-life distribution network for fault analysis.

Maintaining system voltage within the operation band set by the country's grid code is a critical aspect to power system utilities. In lines with the same distribution feeder voltage stability has been analyzed in various literature [21-23]. Real time dynamic voltage stability analysis has been considered as one of the most important applications of synchrophasor technology enabled system operation, which helps power system operators to mitigate cascading catastrophes. Preventive and corrective defense mechanisms to prevent voltage collapses are detailed in [24-26]. Previously, the traditional SPS were simple under voltage load shedding schemes which relied on drop in system voltage. This implies monitoring an already degraded power system [27]. The synchrophasor applications however are complementary in nature, by sensing inception of instability by real-time monitoring of system dynamics instead of analyzing the consequences. Synchrophasor technology improves the anticipation capabilities and avoids post mortem analysis. Voltage stability analysis methods based on phasor measurements from local PMU with very less or no information exchange between different locations being monitored are explained in [28]. The prospective application of real-time $\mu$-PMU measurements in deriving a control algorithm to stabilize the voltage deviation in a distribution feeder is investigated in [29]. Controllers are triggered on support vector machine based prediction of voltage condition of distribution system. Thus, the practical utilization of time synchronized real-time data collected from $\mu$-PMU in distribution system for signaling the most important signals governing power system dynamics is the need of the hour for wide area monitoring, state estimation, fault localization, harmonic analysis and stability analysis etc..

\section{Case description}

A single line diagram showing the system chosen for study, i.e. Paruthippara Substation, a key node out of the eleven $110 \mathrm{kV}$ substations in power system network of Thiruvananthapuram city, is given in Fig. 3.

The two outgoing $110 \mathrm{kV}$ feeders go to $110 \mathrm{kV}$ Medical College substation from where it is fed to Medical College hospital campus. Down lane, the $66 \mathrm{kV}$ stations mentioned further feeds important institutes viz. Vikram Sarabhai Space Centre - a major space research centre of Indian Space Research Organisation (ISRO) which focuses on rocket and space vehicles for India's satellite missions, Technopark - one of world's greenest Technopolis and one among India's largest IT parks, Office of the Reserve 


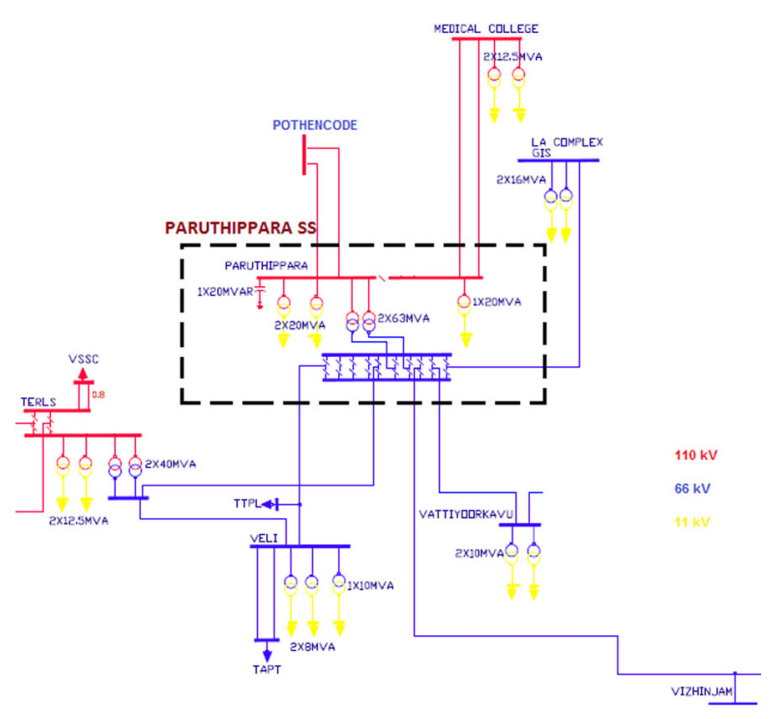

Fig. 3 Single Line Diagram

Bank of India - India's central banking institution and Kerala State Assembly. The $11 \mathrm{kV}$ outgoing feeders also supply power to College of Engineering Trivandrum, an eminent, leading government engineering college in the state. Hence the Paruthippara substation demands 100\% availability and reliability in the journey towards realizing a smart Thiruvananthapuram city. Keeping in view all the above, $110 \mathrm{kV}$ Paruthippara substation was chosen for realizing the cutting-edge applications of synchrophasors by deploying $\mu$-PMUs. The problem statement is based on a grid incident which occurred when the severe tropical cyclone Ockhi wrecked parts of SriLanka and India. Eight coastal districts of Kerala met with damages caused by the fury of Ockhi. On November 30 2017, southern regional load dispatch centre had reported that cyclone Ockhi hit the southern coastal areas of Kerala with widespread rains. The voltage at Thiruvananthapuram grid was out of IEGC band of $1.05 \mathrm{pu}-0.95 \mathrm{pu}$ for 0.9 hours. On November 30 at 12:54 hours, Pothencode-Paruthippara Line-II (PPRA2) tripped on operation of distance protection relay at both ends. The load (base of 100 MVA) in the PPRA2 feeder and outgoing Medical College feeder (PPMC) before tripping is shown in Fig. 4.

Considering the rising load in PPMC outgoing feeders, the operator at Paruthippara SS control room switched off a part of $11 \mathrm{kV}$ loads manually at 12:55. This reduced the load in Pothenocde-Paruthippara Line-I (PPRA1) during the N-1 contingency.However $66 \mathrm{kV}$ ParuthipparaVizhinjam line which feeds Technopark tripped at 12:59 hrs. The $66 \mathrm{kV}$ line was declared faulty on December 1 2017, the next day. Uninterrupted supply to an institute of prime importance like Medical College Hospital campus, in the wake of chaos during Ockhi was
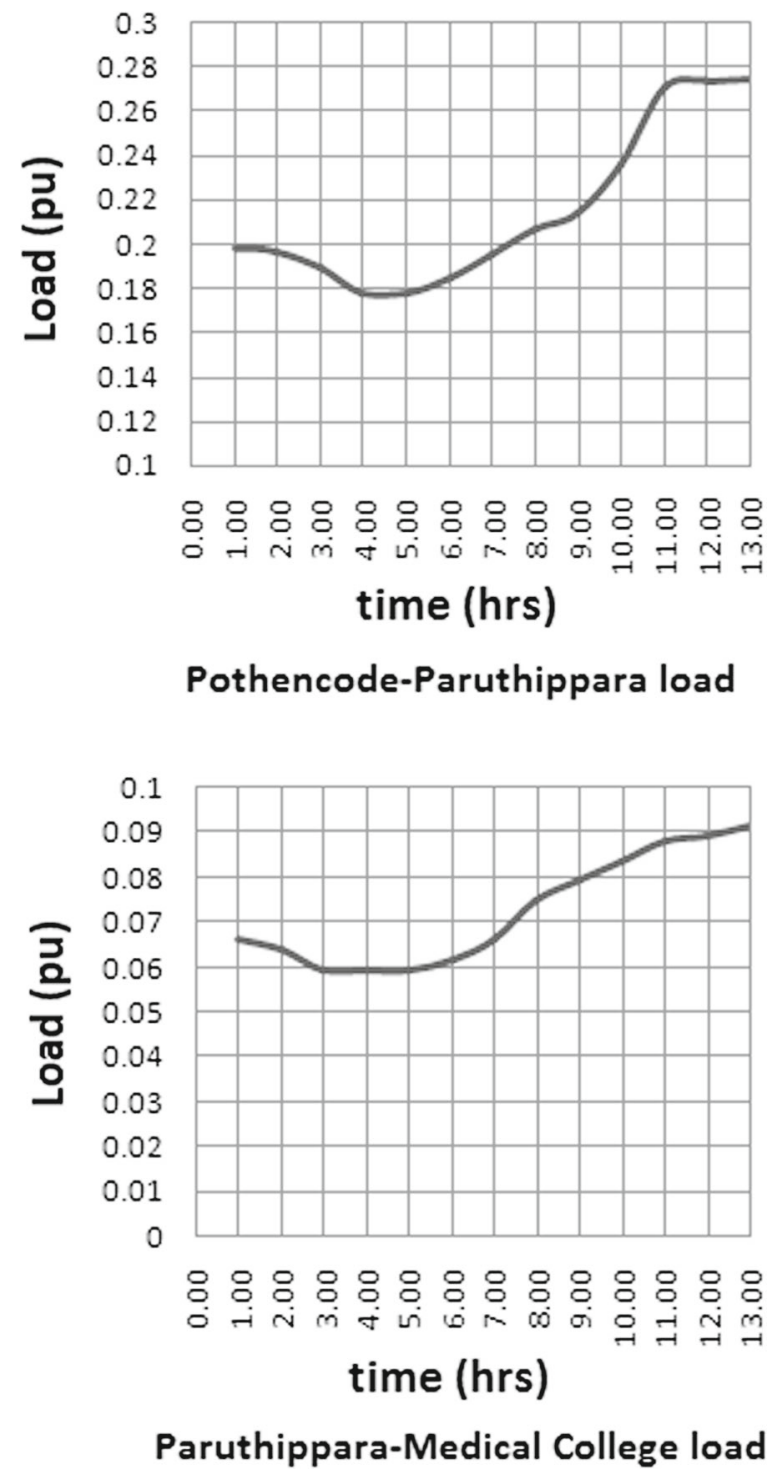

Fig. 4 Incoming and Outgoing feeder Load

completely in the hands of manual operation by control room operators. Based on all of the above, a need was felt to a) enhance the reliability and quality of power supply by providing real-time visualization of system condition using $\mu$-PMU, b) carry out prognosis of system condition using synchrophasors for an automatic and proactive decision support system to aid system operators and c) devise a synchrophasor based SPS scheme, based on local measurement of synchrophasors, which is an automatic and adaptive control logic to help system operators to ensure the stability of Medical College feeder. Research work to achieve the above objectives aids in the journey towards smart city status as well as the aspiration of KSEBL in creating a quality distribution grid by 2022 . 


\section{Proposed methodology}

\subsection{Voltage stability index}

Paruthippara bus is the local network under study termed as node N. The substation with outgoing lines to Paruthippara SS, i.e. Pothencode is Node M. The detailed model is shown in Fig. 5.

An equivalent system at local node $\mathrm{N}$ is formed as shown in Fig. 6.

In order to arrive at the equivalent voltage $V_{e q}$ and system equivalent impedance $Z_{n}$, node $\mathrm{N}$ is divided into two comprising of a) lines with incoming power flows to Node $\mathrm{N}$ and $\mathrm{b}$ ) total outgoing line power, flowing out of Paruthippara node (i.e. the sum of power flows on the outgoing lines). The total outgoing current at Node $\mathrm{N}$ represented by $I_{n}$ is calculated as

$$
\begin{array}{r}
\vec{I}_{n}={\overrightarrow{S_{n}}}^{*} / \vec{V}_{n}{ }^{*} \\
=\frac{\left(\vec{V}_{u 1}-\vec{V}_{n}\right)}{Z_{1}}+\frac{\left(\vec{V}_{u 2}-\vec{V}_{n}\right)}{Z_{2}} \\
=Y_{1} \vec{V}_{u 1}+Y_{2} \vec{V}_{u 2}-\vec{V}_{n}\left(Y_{1}+Y_{2}\right) \\
Y_{n}=Y_{1}+Y_{2} \\
\vec{V}_{e q}=\left(Y_{1} \vec{V}_{u 1}+Y_{2} \vec{V}_{u 2}\right) / Y_{n} \\
\vec{V}_{e q}=\vec{I}_{n} Z_{n}+\vec{V}_{n} \\
\text { where } Z_{n}=1 / Y_{n}
\end{array}
$$

The equivalent impedance at Node $\mathrm{N}$ comprises of $\mathrm{Z} 1$ and $\mathrm{Z} 2$ the impedance of incoming two lines and also considers the reactive charging powers at line ends denoted by B1 \& B2. The line impedance parameters of incoming Pothencode line 1 and 2 can be utilized to obtain equivalent local system impedance, $Z_{n}$. The local voltage and current phasors can be obtained from $\mu$-PMU proposed to be installed in Paruthippara bus. The synchrophasor data can be used to arrive $V_{e q}$. In order to encompass the effect of the power system network external to Paruthippara SS, a system model is formed with an equivalent

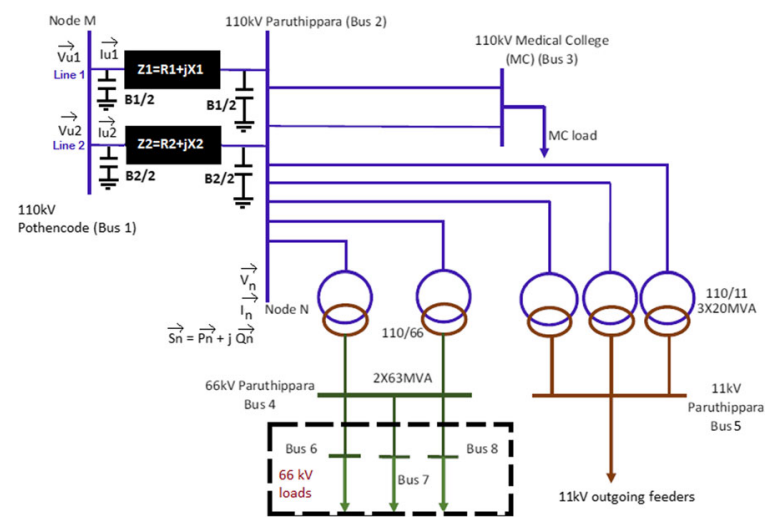

Fig. 5 Test system - Paruthippara SS

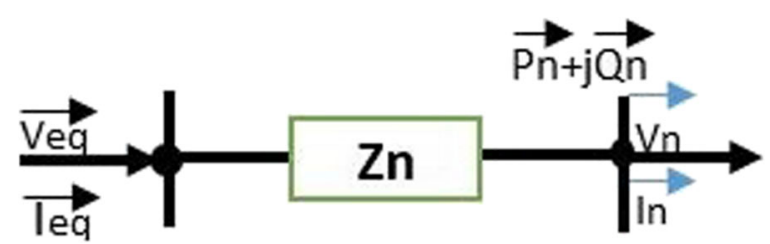

Fig. 6 Equivalent system at local node $\mathrm{N}$

voltage source and a source impedance added to the local equivalent system model of Fig. 5, as shown in Fig. 7.

The equivalent system model with voltage source $\vec{E}_{q}$ and source impedance $Z_{q}$ will hold true, with effect same as that of an external power system network, if the following equations are satisfied. These equations imply that voltage phasors and power flows identical to original system are ensured for the equivalent model formed.

$$
\begin{array}{r}
\left(P_{m}+j Q_{m}\right)^{*}=\vec{V}_{e q}^{*} \overrightarrow{I_{e q}} \\
\vec{I}_{n}=\vec{I}_{e q}=\frac{\left(\vec{E}_{q}-\vec{V}_{e q}\right)}{Z_{q}}=\frac{\left(\vec{V}_{e q}-\vec{V}_{n}\right)}{Z_{n}} \\
\frac{Z_{q}}{Z_{n}}=\frac{\left(\vec{E}_{q}-\vec{V}_{e q}\right)}{\left(\vec{V}_{e q}-\vec{V}_{n}\right)}
\end{array}
$$

where, $\mathrm{Pm}$ and $\mathrm{Qm}$ are the incoming real and reactive powers flowing into the local node $\mathrm{N}$, i.e. the sum of incoming power flows through each of the incoming lines to Node N. Introducing a complex coefficient,

$$
\begin{array}{r}
r=\left(Z_{q}+Z_{n}\right) / Z_{n} \\
\vec{E}_{q}=r \vec{V}_{e q}+(1-r) \vec{V}_{n}
\end{array}
$$

Considering two equilibrium states of the system under consideration, the equivalent source voltage and source impedance will remain same as shown in equations below.

$$
\begin{aligned}
& \vec{E}_{q}=(r) \overrightarrow{V_{e q 1}}+(1-r) \overrightarrow{V_{n 1}} \\
& \overrightarrow{E_{q}}=(r) \overrightarrow{V_{e q 2}}+(1-r) \vec{V}_{n 2}
\end{aligned}
$$

Equating above,

$$
r=\frac{1}{1-\left(\left(\overrightarrow{V_{e q 1}}-\overrightarrow{V_{e q 2}}\right) /\left(\overrightarrow{V_{n 1}}-\overrightarrow{V_{n 2}}\right)\right)}
$$

Evaluating $r$ from Eq. (4) and substituting in Eq. (3) will give equivalent voltage source. Knowing value of $\mathrm{r}$ and $Z_{n}$, the source impedance $Z_{q}$ can also be found out. Now we

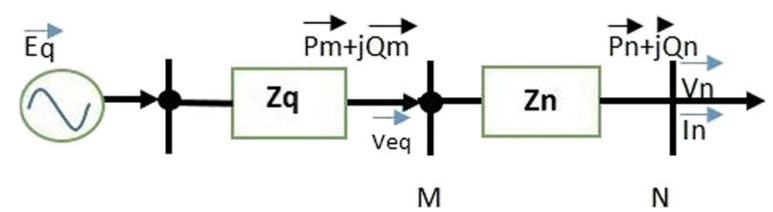

Fig. 7 System Model 
represent the voltage phasors and impedance in rectangular form and separate the real and imaginary parts as in the Eqs. (6) and (7) derived below.

$$
\begin{array}{r}
\vec{E}_{q}=E_{q} \angle \theta_{q}, \vec{V}_{n}=V_{n} \angle \theta_{n} \\
\vec{I}_{n}=\left(\vec{E}_{q}-\vec{V}_{n}\right) / Z \text {, where } Z=R+j X=Z_{q}+Z_{n} \\
\vec{S}_{n}=\vec{V}_{n} \vec{I}_{n}^{*} \\
P_{n} R+Q_{n} X=V_{n} \cos \theta_{n}\left(E_{q} \cos \theta_{q}-V_{n} \cos \theta_{n}\right) \\
+V_{n} \sin \theta_{n}\left(E_{q} \sin \theta_{q}-V_{n} \cos \theta_{n}\right) \\
P_{n} X-Q_{n} R=V_{n} \cos \theta_{n} E_{q} \sin \theta_{q}-E_{q} \cos \theta_{q} V_{n} \sin \theta_{n}
\end{array}
$$

The equivalent system model for Paruthippara node $\mathrm{N}$ built using local synchrophasor measurements will have a mathematical solution for the Eqs. (6) and (7), if the power system is at a stable state [30]. The singularity of the Jacobian (J) determines solvability of Eqs. (6) and (7).

$$
J=\left[\begin{array}{ll}
\left(E_{q} \cos \theta_{q}-2 V_{n} \cos \theta_{n}\right) & E_{q} \sin \theta_{q}-2 V_{n} \sin \theta_{n} \\
E_{q} \sin \theta_{q} & -E_{q} \cos \theta_{q}
\end{array}\right]
$$

If a mathematical solution does not exist for the system model of node $\mathrm{N}$ given by Eqs. (6) and (7), it implies $\operatorname{Det}(J)=0$, i.e. the operational voltage does not exist at the node $\mathrm{N}$ and thus, loss of voltage stability. The determinant of Jacobian (as in Eq. (9)) thus serves as an index for analyzing dynamic voltage stability index (VSI) of Paruthippara SS.

$$
\text { Stability Index }=2 E_{q} V_{n}\left(\cos \theta_{q n}+\sin \theta_{q n}\right)-E_{q}^{2},
$$

where $\theta_{q n}=\theta_{q}-\theta_{n}$ The stability index calculated in Eq. (9) is utilized to calculate VSI of $110 \mathrm{kV}$ Medical College substation and further in determining SPS initiation. During $\mathrm{N}-1$ contingency at Paruthippara, if a decline in VSI of Medical College bus is observed, an SPS can be initiated based on rate of change of VSI (RVI), to shed the down lane load to maintain reliable supply at Medical College hospital campus. A threshold of RVI is to be set for each monitored node to initiate the SPS and shed load.

$$
R V I=\frac{|V S I(t)-V S I(t-1)|}{V S I(t-1)} \%
$$

Once the voltage instability condition is identified, weakest bus at Paruthippara SS which contribute to the instability at Medical College during $\mathrm{N}-1$ contingency at Paruthippara SS is determined. This is to decide the location of load curtailment as explained in next section.

\subsection{Load curtailment strategy}

Load curtailment being the answer to the detailed contingency in power system network, the best suitable location of load curtailment needs to be found. Bus modal analysis and determination of participation factor is proven to be an effective methodology as presented in [31-33]. In order to improve the stability of the system, shedding the load at weak buses is the best solution. Modal analysis involves evaluating eigenvalues and the corresponding eigen vectors of the reduced Jacobian matrix. As voltage stability is focused in this study, the reduced Jacobian matrix is considered instead of system state matrix. The magnitudes of eigen value provide an accurate estimation of proximity to voltage instability by recognizing different unstable modes. Eigen vectors help in arriving at the weakest node contributing to the unstable mode. The right and left eigen vectors help in arriving at the participation factors.

For modal analysis power system network is modeled as

$$
\left[\begin{array}{l}
\Delta P \\
\Delta Q
\end{array}\right]=J\left[\begin{array}{l}
\Delta \theta \\
\Delta V
\end{array}\right]
$$

where $\mathrm{J}$ is the Jacobian matrix and $\Delta P, \Delta Q, \Delta V$ and $\Delta \theta$ are changes in real power, reactive power, bus voltage and angle respectively.

$$
\begin{array}{r}
\operatorname{As} \Delta P=0, \Delta Q=J_{R} \Delta V, \\
\text { reduced Jacobian } J_{R}=\left[J_{Q V}-J_{Q \theta} J_{P \theta}{ }^{-1} J_{P V}\right]
\end{array}
$$

Taking $\xi$ as the right eigen vector matrix of $J_{R}, \Lambda$ as the diagonal eigen value matrix and $\eta$ as the left eigen vector matrix of $J_{R}, J_{R}=\xi \Lambda \eta$. The participation factor, $P_{m n}$ of the $m^{\text {th }}$ bus to the $n^{\text {th }}$ mode is evaluated using the left and right eigen vectors. The value corresponding to the $n^{\text {th }}$ critical mode of the system is given as $P_{m n}=\xi_{m n} \eta_{n m}$. The load buses which are the suitable candidates for load shedding can be identified using the magnitude of participation factor, the highest contributing the most to the voltage instability. The VSI derived in this work serves as an index for identifying the weakest bus contributing to instability in power system, thus serving as a comprehensive solution for voltage instability detection. The load bus with lowest VSI is the weakest bus contributing to instability. Flowchart of the proposed SPS is given in Fig. 8. A comparison of various notable concepts used and assumptions made while deriving voltage stability indices in previous research works of past 10 years is given in Table 1.

\subsection{PMU deployment}

For effective sampling of phasor data and calculation of stability index, two $\mu$-PMUs, one each at Paruthippara and Medical College bus are proposed to be installed at present. The measurement values of current phasor are collected from substation line current transformer, so that all incoming line current add up to give total bus incoming current. This is similar as the bus current is wired up for bus differential protection. The bus voltage phasor can be sampled from bus capacitive voltage transformer. The $\mu$-PMU is connected to a $\mu$-PDC for data analytics through a network infrastructure capable of sending data streams using local area network infrastructure. The communication network is to be built to comply with 


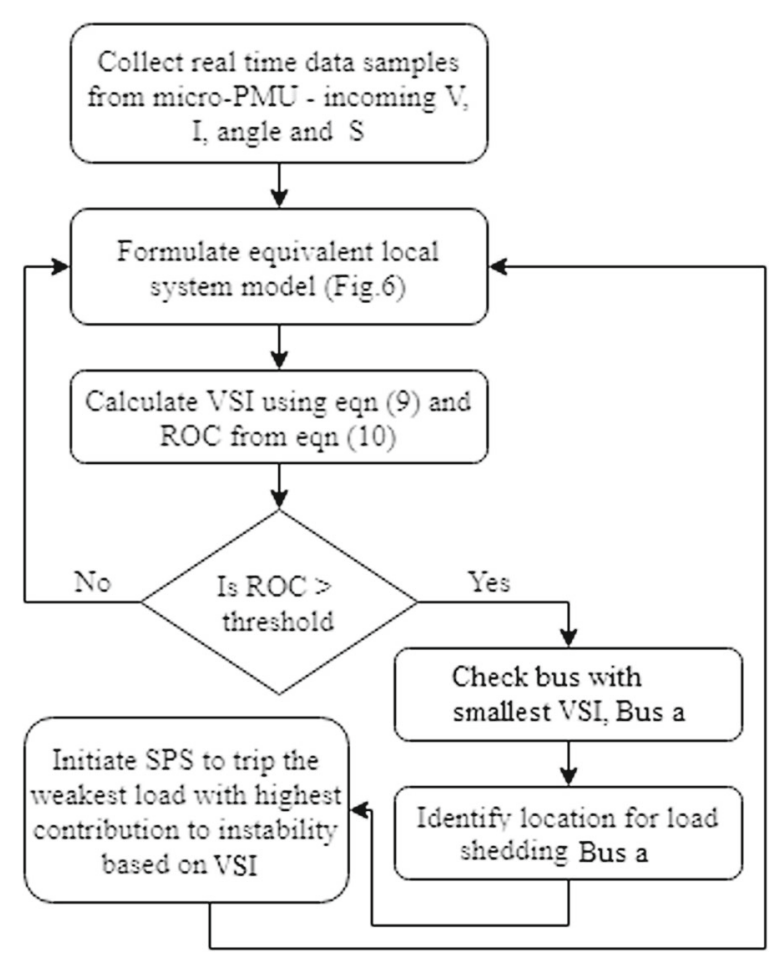

Fig. 8 Flowchart of the proposed scheme the standard IEC 61850 protocol. The voltage and current phasor measurements are to be streamed under IEEE standard C37.118 protocol. A GPS time synchronized Precision Time Protocol (PTP) master as per the IEEE 1588 standard is proposed as a perfect fit for generating clock signals for synchronization upto nanoseconds.The proposed $\mu$-PMUs sample four fundamental three phase measurements i.e. voltage magnitude, voltage phase angle, current magnitude, and current phase angle. The sampling rate is considered as 100 samples in a second, which would be 2 samples per cycle for a $50 \mathrm{~Hz}$ system. This upgradation in data sampling rate is critical considering the leap from standard 2-10 seconds SCADA system sampling rate. $\mu$-PMU deployment single line diagram with details is given in Fig. 9. If the proposed scheme is to be utilized for automatic load shedding procedure, further $\mu$ PMUs need to be installed in down lane $66 \mathrm{kV}$ and $11 \mathrm{kV}$ stations.

\section{Simulation results and discussion}

The test system presented in Fig. 5 was simulated in MAT$\mathrm{LAB}$ using actual grid data and real-time measurements collected from Paruthippara (PPRA) substation.

Case 1 The base system was studied by increasing the load in outgoing Medical College (MC) feeders in steps of load factor $\lambda$. While increasing the load, the voltage limits were kept as per IEGC band for all feeders except $11 \mathrm{kV}$. It

Table 1 A comparison of concepts on voltage stability indices

\begin{tabular}{|c|c|c|}
\hline Reference & Concept & Assumption \\
\hline [34] & $\begin{array}{l}\text { Two bus system considered, discriminant of the voltage } \\
\text { quadratic equation } \geq 0 \text {. }\end{array}$ & Shunt admittance is neglected. \\
\hline [35] & $\begin{array}{l}\text { Two bus system considered, discriminant of the voltage } \\
\text { quadratic equation } \geq 0 \text {. }\end{array}$ & $\begin{array}{l}\text { Shunt admittance is neglected. } \\
\text { The angular separation of sending and receiving end bus } \\
\text { voltage } \delta \approx 0 \text {. }\end{array}$ \\
\hline [36] & Same concept as above line voltage stability indices. & Line resistance \& shunt admittance neglected. \\
\hline [37] & Same concept as above line voltage stability indices. & $\begin{array}{l}\text { Shunt admittance is neglected. } \\
\text { The angular separation of sending and receiving end bus } \\
\text { voltage } \delta \approx 0 \text {. }\end{array}$ \\
\hline [38] & $\begin{array}{l}\text { Limiting the maximum power transferable through a transmis- } \\
\text { sion line. }\end{array}$ & $\begin{array}{l}\text { Shunt admittance is neglected. } \\
\text { Power factor assumed to be constant. }\end{array}$ \\
\hline [39] & $\begin{array}{l}\text { The voltage drop across equivalent Thevenin impedance = } \\
\text { load voltage at the point of voltage collapse }\end{array}$ & $\begin{array}{l}\text { Equivalent Thevenin impedance connected to sending bus is } \\
\text { neglected. } \\
\text { Ideal voltage source assumed at sending end bus. }\end{array}$ \\
\hline [40] & Discriminant of the voltage quadratic equation $\geq 0$ & $\begin{array}{l}\text { Shunt admittance is neglected. } \\
\text { Voltage angle assumed to be very small. }\end{array}$ \\
\hline [41] & $\begin{array}{l}\text { The largest value of difference in voltage magnitude of two } \\
\text { buses is the correction factor } \beta \text {. }\end{array}$ & $\begin{array}{l}\text { The voltage of the generator closest to the load bus is taken as } \\
\text { the Thevenin voltage of the load bus. }\end{array}$ \\
\hline [42] & $\begin{array}{l}\text { Based on \% diversity, between moving average value, RMS of } \\
\text { N PMU values of load bus voltage, Vi and ith sampled data }\end{array}$ & The generator voltages are held constant. \\
\hline Present work & $\begin{array}{l}\text { An equivalent system of the local network is modeled with } \\
\text { an equivalent source and impedance encompassing the effect } \\
\text { of entire power system network external to the node under } \\
\text { consideration }\end{array}$ & $\begin{array}{l}\text { Angular separation of sending and receiving end bus voltage } \\
\theta_{q n} \text { is considered as it carries important information regarding } \\
\text { system dynamics. } \\
\text { Local synchrophasor data utilized. }\end{array}$ \\
\hline
\end{tabular}




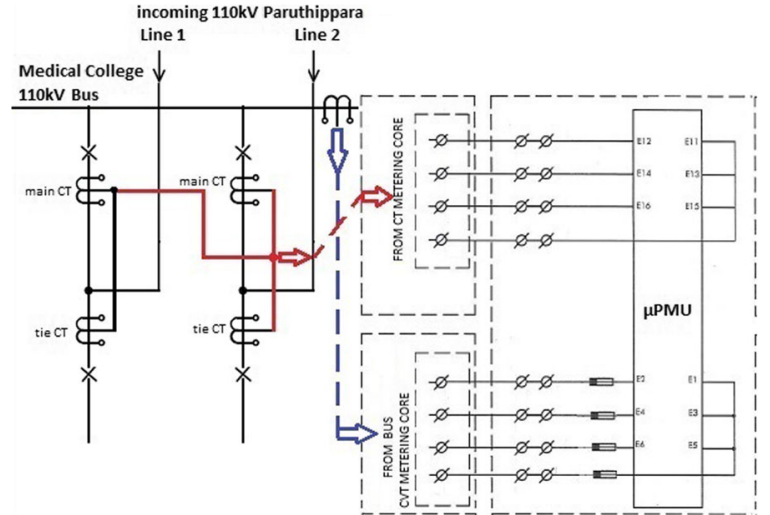

Fig. 9 Single Line Diagram of PMU deployment

was observed that the voltages in $110 \mathrm{kV} P P R A$ bus (bus 2), $110 \mathrm{kV} \mathrm{MC} \mathrm{bus} \mathrm{(bus} \mathrm{3)} \mathrm{and} 66 \mathrm{kV}$ bus (bus 4) declines as seen in Fig. 10.

The angular separation ( $\delta$ ) with respect to Pothencode bus (incoming $110 \mathrm{kV}$ ) as reference, is also seen to increase with increasing load at MC as seen in Fig. 10. Now, in order to study the nature of the voltage stability index derived, the lower voltage limit of all buses were set as zero and the load in outgoing MC feeders in steps of load factor $\lambda$. The voltage stability indices of PPRA $110 \mathrm{kV}$ bus and MC 110 $k V$ bus are calculated and plotted in Fig. 11.
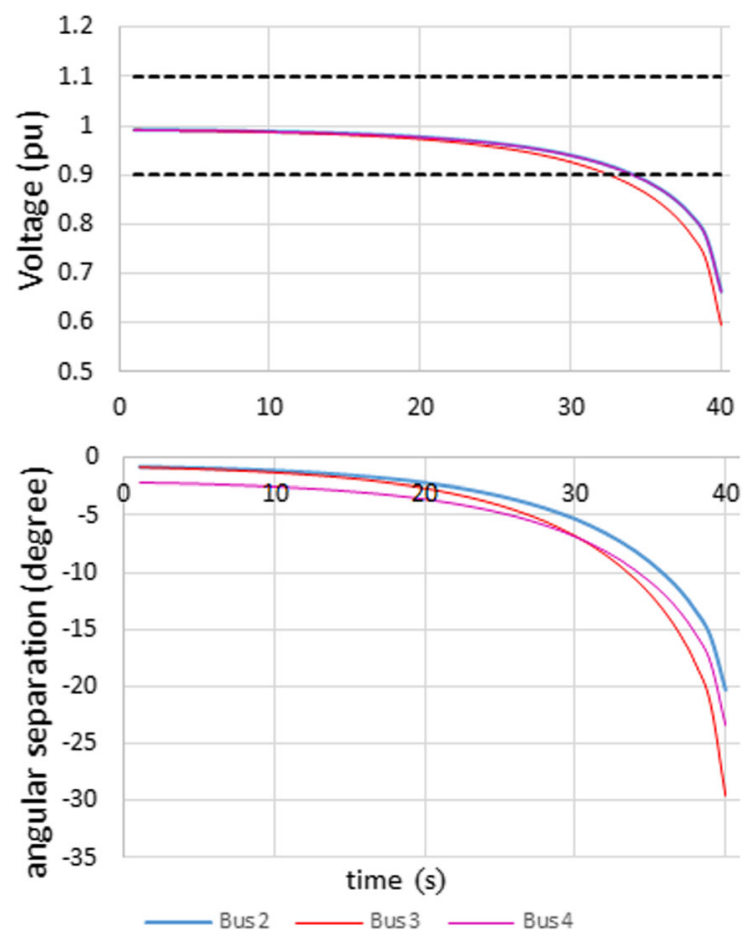

Fig. 10 Bus voltage and angular separation on MC load rise
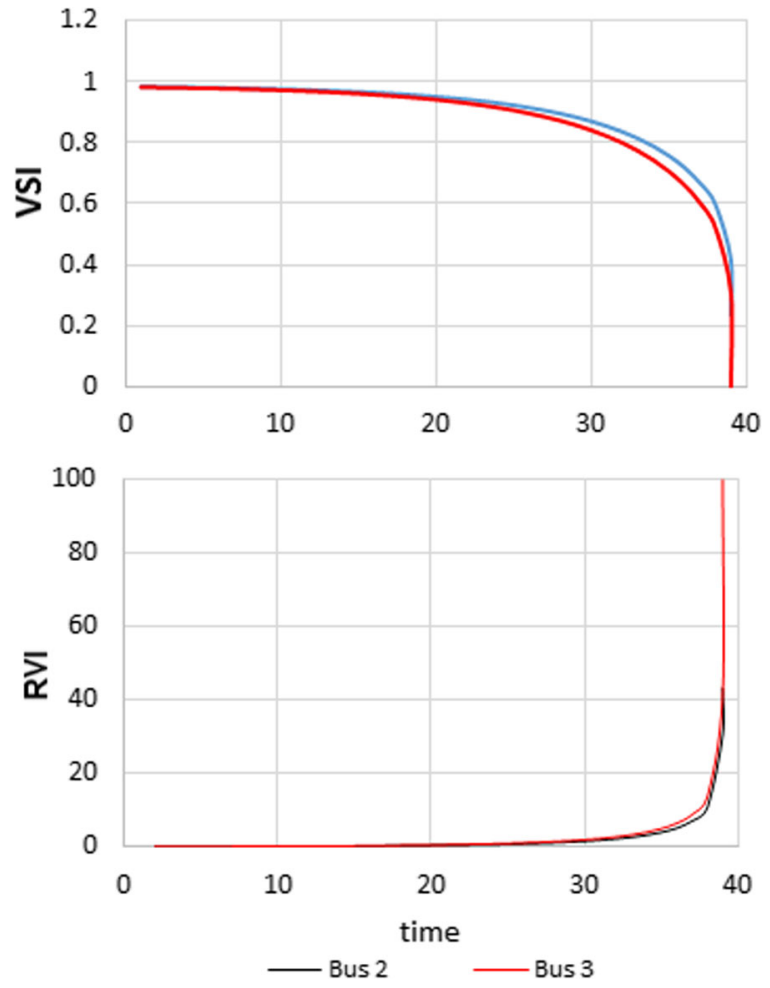

Fig. $11 \mathrm{VSI}$ and RVI on MC load rise

It can be seen that with an increase in load at MC, as expected, the voltage stability index of MC bus starts decreasing. The decline of VSI is reflected in Paruthippara $110 \mathrm{kV}$ bus as well. The VSI of MC and PPRA bus approaches zero when power flow fails to converge.

Case 2 Next the impact of N-1 contingency at PPRA bus is analyzed. The load in outgoing MCfeeders are increased in steps of load factor $\lambda$ keeping the IEGC voltage limits for all feeders except $11 \mathrm{kV}$. The incoming PPRA bus is also seen to approach zero. Line 2 (PPRA2) was tripped almost near to 1.5 times full load at MC SS. The VSI of both Paruthippara and MC stations were seen to approach zero once PPRA2 got tripped indicating voltage instability. The VSI computed and rate of change of VSI (RVI) is shown in Fig. 12.

From the figure it can be seen that RVI \% is an ideal candidate to initiate corrective action for the instability as seen by the drop in VSI.

Case 3 Next, modal analysis was carried out on the base system to identify the critical mode and the weakest bus at Paruthippara SS. Table 2 shows the eigen values of inverse reduced Jacobian matrix.

As seen, 0.3801 is the highest value and corresponds to mode 2. Corresponding to mode 2 the values from eigen 

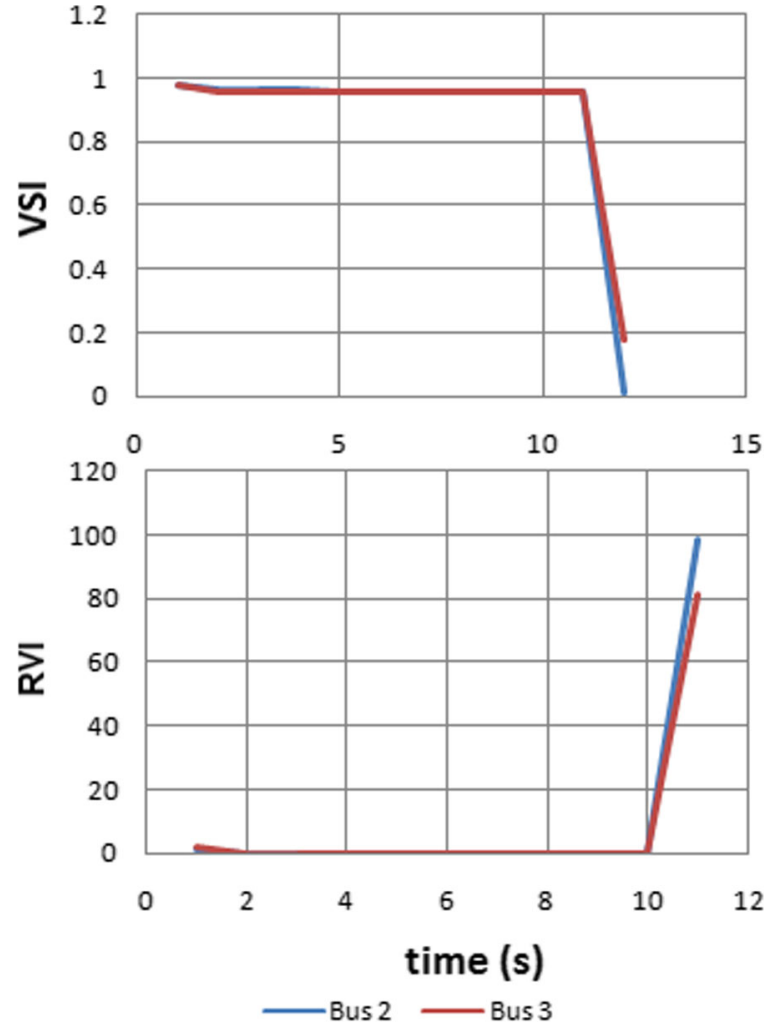

Fig. 12 Voltage Stability Index and RVI on N-1 contingency

vector shows that bus 4 has the critical value. Thus the 66 $k V$ bus (bus 4) at Paruthippara SS is the weakest bus. The voltage stability index values also shows that Bus 4, the $66 \mathrm{kV}$ bus is the weakest load bus at Paruthippara as shown in Fig. 13.

Next the modal analysis was repeated on the system in case 2, i.e. with PPRA2 tripped at 1.5 times full load at Medical College feeder. The critical eigen vector entry and corresponding bus is shown in Fig. 14. It can be observed that $66 \mathrm{kV}$ bus at Paruthippara is the weakest bus contributing to voltage instability on $\mathrm{N}-1$ contingency. The load participation factors are then computed for the down lane $66 \mathrm{kV}$ feeders of the $66 \mathrm{kV}$ bus at Paruthippara. The participation factors of the loads are shown in Fig. 14.

It can be seen that $66 \mathrm{kV}$ load at bus 7 contributes most to the instability followed by bus 8 . Voltage stability index

Table 2 Eigen values and Eigen vectors at Paruthippara SS

\begin{tabular}{llll}
\hline Eigen value & & \multicolumn{2}{l}{ Eigen vector (mode 2) } \\
\hline 1 & 0.0000 & Bus 1 & Swing bus \\
2 & $\mathbf{0 . 3 8 0 1}$ & Bus 2 & 0.1036 \\
3 & 0.0575 & Bus 3 & 0.1050 \\
4 & 0.0022 & Bus 4 & $\mathbf{0 . 4 6 9 6}$ \\
5 & 0.0014 & Bus 5 & 0.1129 \\
\hline
\end{tabular}

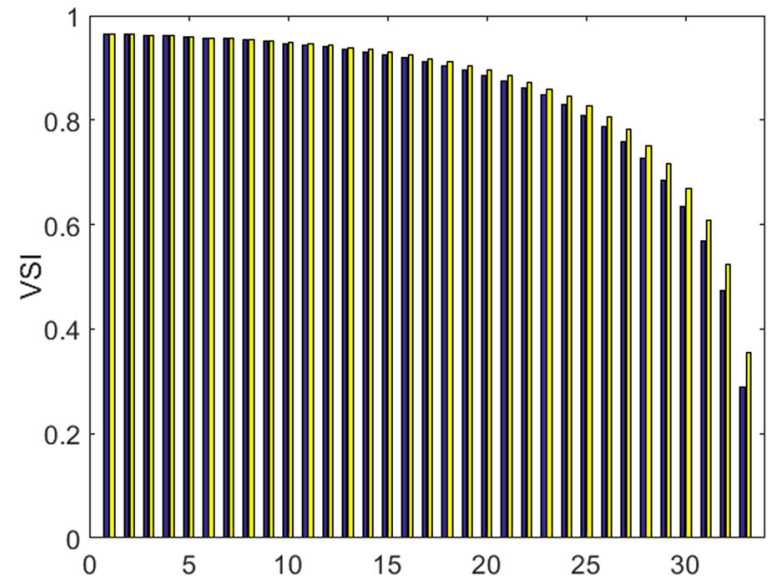

Fig. 13 VSI as indicator of weakest bus

values also show that Bus 7 is the weakest bus as it has the lowest value of VSI approaching zero during the contingency. Accordingly while configuring the special protection scheme to maintain voltage stability at $M C$ and ensure reliable power supply to MC hospital, the load curtailment shall begin with bus 7 followed by bus 8 if required.

Case 4 Validation of the proposed SPS for mitigating voltage instability is presented as Case 4. The load in outgoing Medical College feeders are increased in steps of load factor $\lambda$ keeping the Indian Electricity Grid Code (IEGC) voltage limits for all feeders except $11 \mathrm{kV}$. The incoming Paruthippara Line 2 (PPRA2) is tripped at almost near to full load at Medical College SS. As proposed in the flowchart of Fig. 7, the SPS scheme monitors the value of
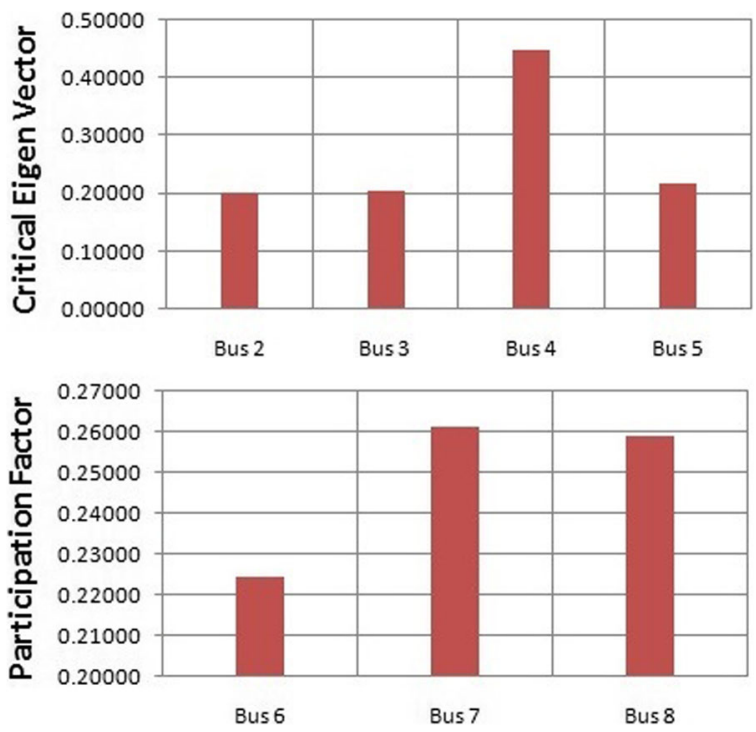

Fig. 14 Critical eigen vector entry and participation factor 
VSI of Medical College bus. The SPS is initiated based on value of rate of change of VSI (RVI) of MC bus. In the present study RVI threshold is fixed at $10 \%$ based on the nature of RVI observed in Fig. 10 earlier. Once RVI is above threshold, the highest contributor to instability i.e. load at bus 7, based on the lowest value of VSI, is first isolated. The value of RVI is rechecked as to whether within the threshold limit. The critical eigen vectors and participation factors are also recalculated after each load curtailment to monitor the highest contributor to instability and changes due to network reconfiguration. In this study bus 7 remained the highest followed by bus 8. As the RVI is not within limits even after shedding load at bus 7 , the next highest contributor i.e. the load at bus 8 is also isolated. The VSI and RVI of MC bus is shown in Fig. 15.

The bus voltages and angular separation ( $\delta$ ) of Paruthippara and Medical College buses are as seen in Fig. 16.

Initially as the load in MC feeders increase, the VSI of MC bus does not show any appreciable change while VSI suddenly declines and approaches zero as PPRA2 is tripped. As the SPS is initiated when the RVI reaches $10 \%$, the VSI profile improves and with shedding of both loads becomes steady. Similarly, the voltage of Paruthippara and MC bus starts falling gradually but declines suddenly on tripping PPRA2. As the SPS is initiated, the voltage profile improves and becomes steady. The angular separation which was showing an increasing trend settles to a steady value on initiation of SPS and isolation of $66 \mathrm{kV}$ loads in bus 7 and 8. Thus the special protection scheme based on voltage stability index using local $\mu-P M U$ data is seen to be effective in maintaining the voltage stability of Medical College bus and Paruthippara bus as well.
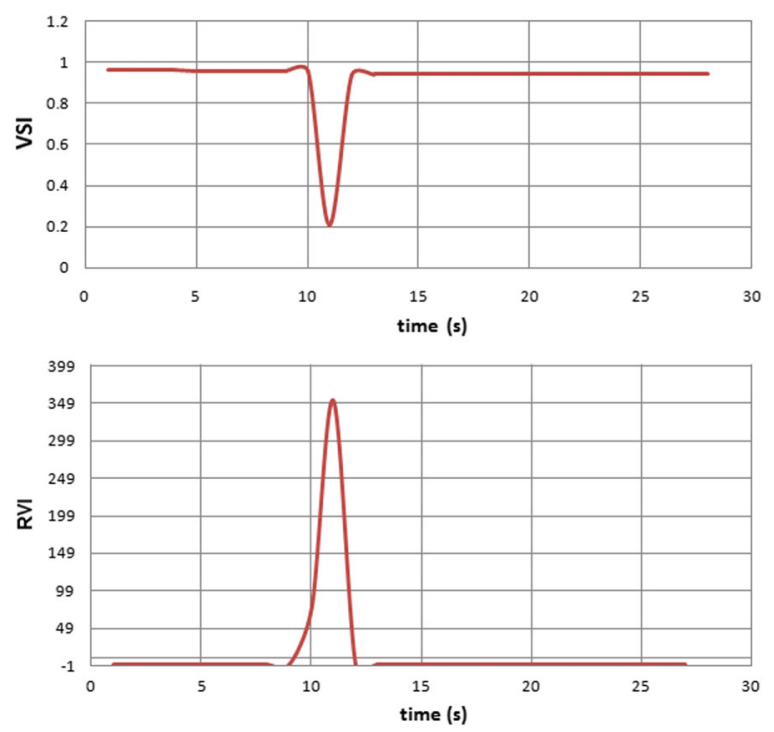

Fig. $15 \mathrm{VSI}$ and RVI of MC bus on SPS initiation
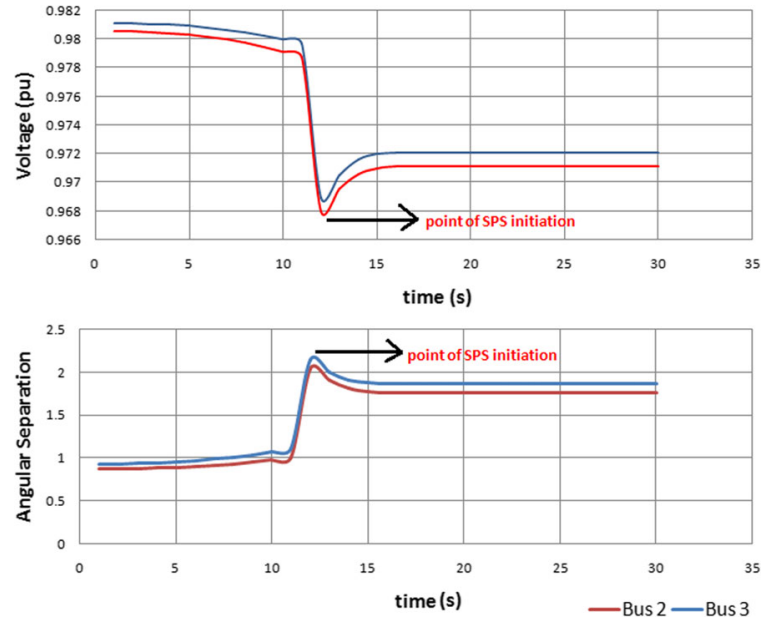

Fig. 16 Bus parameters on SPS initiation

This ensures a reliable power supply to MC hospital campus and add on to the meticulous efforts taken by power system operations team for upgradation of power system protection and automation, in the journey towards smart Thiruvananthapuram city.

Case 5 The characteristics of the voltage stability index derived in the present work have been compared with the index derived in [42]. The study assumes availability of data from PMU using which a dynamic voltage stability criterion i.e. voltage stability risk index (VSRI) [42] is devised to analyze the voltage stability of system in real time. The VSRI at each load bus is used for deciding upon suitable locations for the load curtailments to mitigate voltage instability. The scheme using VSRI was chosen for study as comparison has been made with conventional under frequency load shedding scheme as well as another load shedding scheme in [42]. As in [42], the New England 10-machine 39-bus system shown in Fig. 17 has been chosen for testing VSI derived in the present study.

While VSI is derived based on the concept of singularity of the Jacobian matrix of equivalent system model, VSRI is based on percentage diversity of PMU sampled voltage. A system has stable post fault voltage if VSRI of all buses converge to zero, while the bus with most negative deviation is the weakest one giving highest contribution to instability. The scheme in [42] works in two stages and depends on Lindex based voltage stability analysis for post disturbance analysis. A case of outage of generator at bus 33 at $6.1 \mathrm{~s} \mathrm{sim-}$ ulated, which causes a power deficit of $6.45 \mathrm{pu}$. Voltage at selected critical buses post contingency is shown in Fig. 18.

It can be observed that voltage collapses in Bus 19 and 20. Now VSI is calculated for the critical buses and characteristics compared with VSRI. The study in [42] proposes that if the most negative value of VSRI at the load buses 


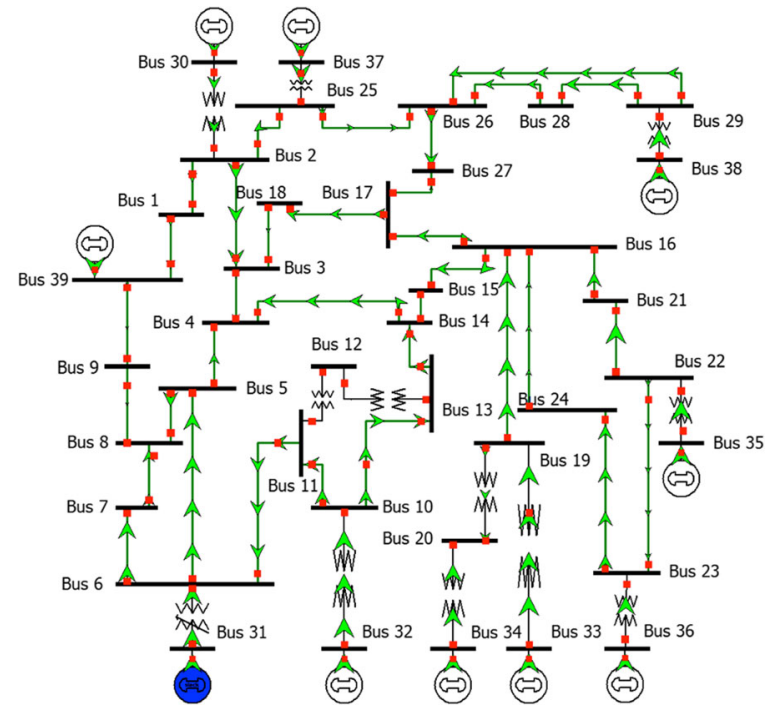

Fig. 17 10-machine 39 bus New England system [43]

ie.VSRI min is lesser than VSRI $I_{\text {th }}$ after a set time, the system is considered voltage unstable. Thus, VSRI is evaluated after a time interval $t_{\text {set }}=5 \mathrm{~s}$ from point of disturbance $=$ $6.1 \mathrm{~s}$ at 11.1s and the system is considered voltage unstable as VSRI min is below threshold value. Load shedding is carried out at $11.3 \mathrm{~s}$ in [42]. VSRI (from [42]) and VSI (from present paper) plots post contingency are shown in Fig. 19.

The VSI approaches zero at 8.2 s indicating singularity of Jacobian, i.e. voltage instability. The RVI plot in Fig. 20 also indicates impending voltage collapse as it crosses threshold at 8.0s.

As rate of change of VSI is utilized the RVI index derived in the present study helps in early detection of impending voltage collapse. The collapsing bus voltage angular separation in Fig. 21, which is included in VSI, is a key indicator which contributes to early detection.

In the scheme using VSRI load shedding of 3.01pu happens in Bus 20 at 11.3s initiating the system corrective

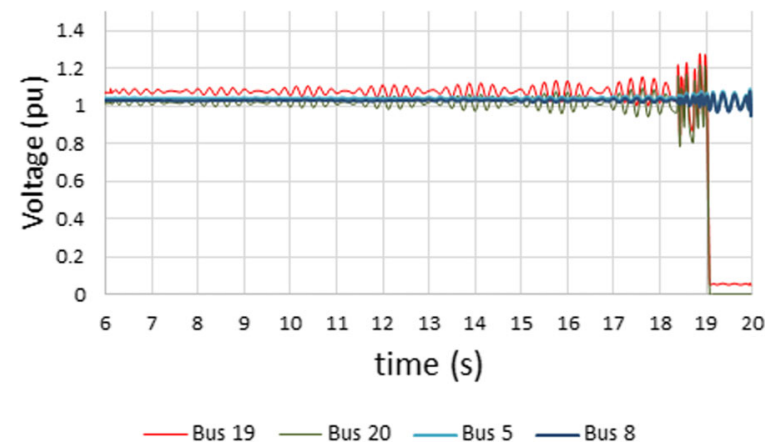

Fig. 18 Voltage profile post contingency
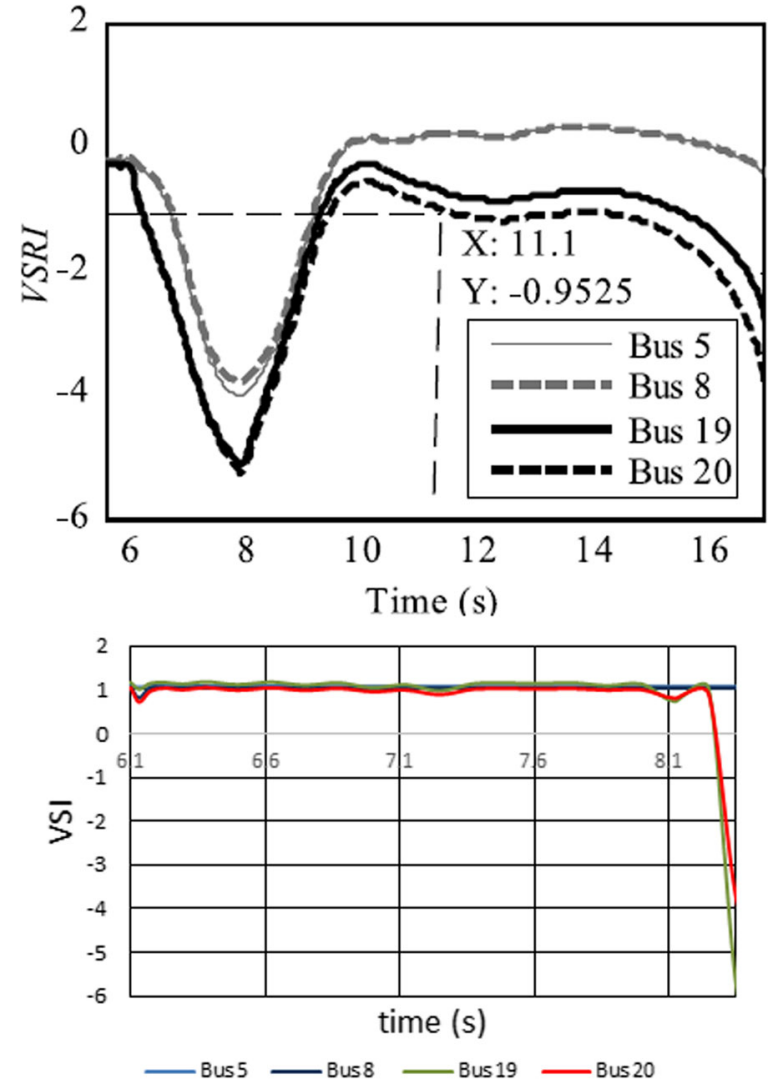

Fig. $19 \mathrm{VSRI}$ and VSI post contingency

action. The load shedding action is triggered at 8.0s based on RVI in the scheme using VSI. Bus 19 is seen to be the weakest bus from RVI and VSI values followed by Bus 20. $3.01 \mathrm{pu}$ at Bus 20 is shed at 8.01s. The voltage is seen to approach acceptable limits as in Fig. 22. However as discussed in [42] post load shedding generation rescheduling has to be done to attain an optimal operating point. Thus $R V I$ serves as a key indicator in detecting impending voltage instability well on time and VSI serves as an indicator

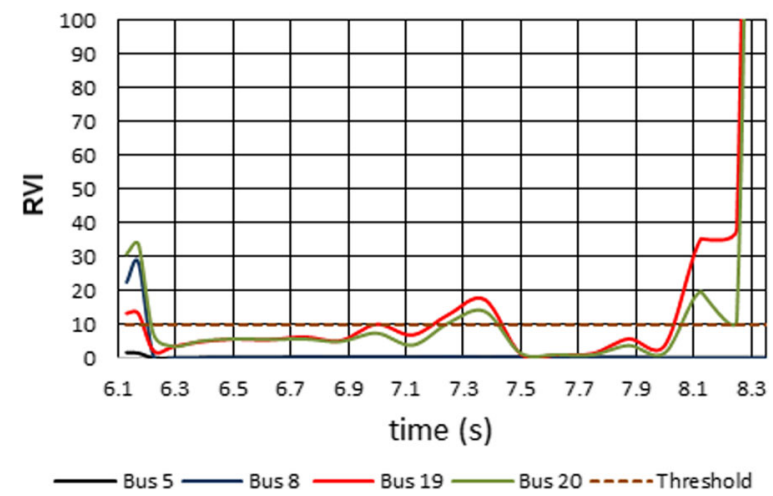

Fig. $20 \mathrm{RVI}$ post contingency 


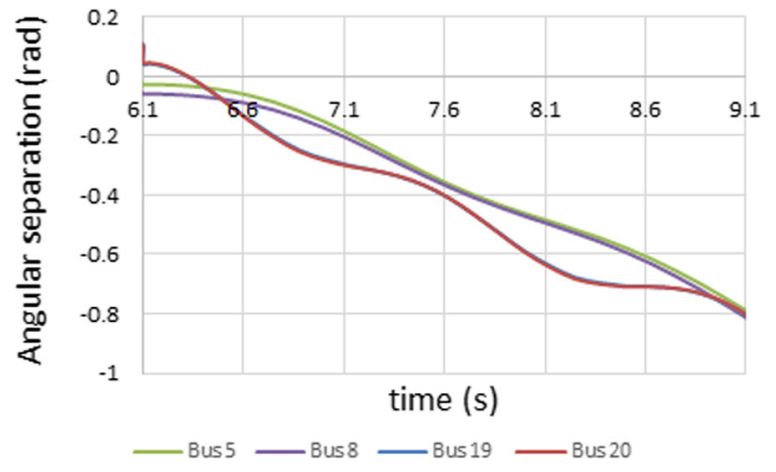

Fig. 21 Bus voltage angular separation post contingency

of the weakest bus contributing towards instability. Further only local phasor values are required for formulating the stability index VSI and further threshold using RVI. The effect of entire power system network external to node under study is encompassed, without the need for intricate power system details.

\section{Conclusion}

The study derives critical indices to detect contingency related voltage instability conditions and designs System
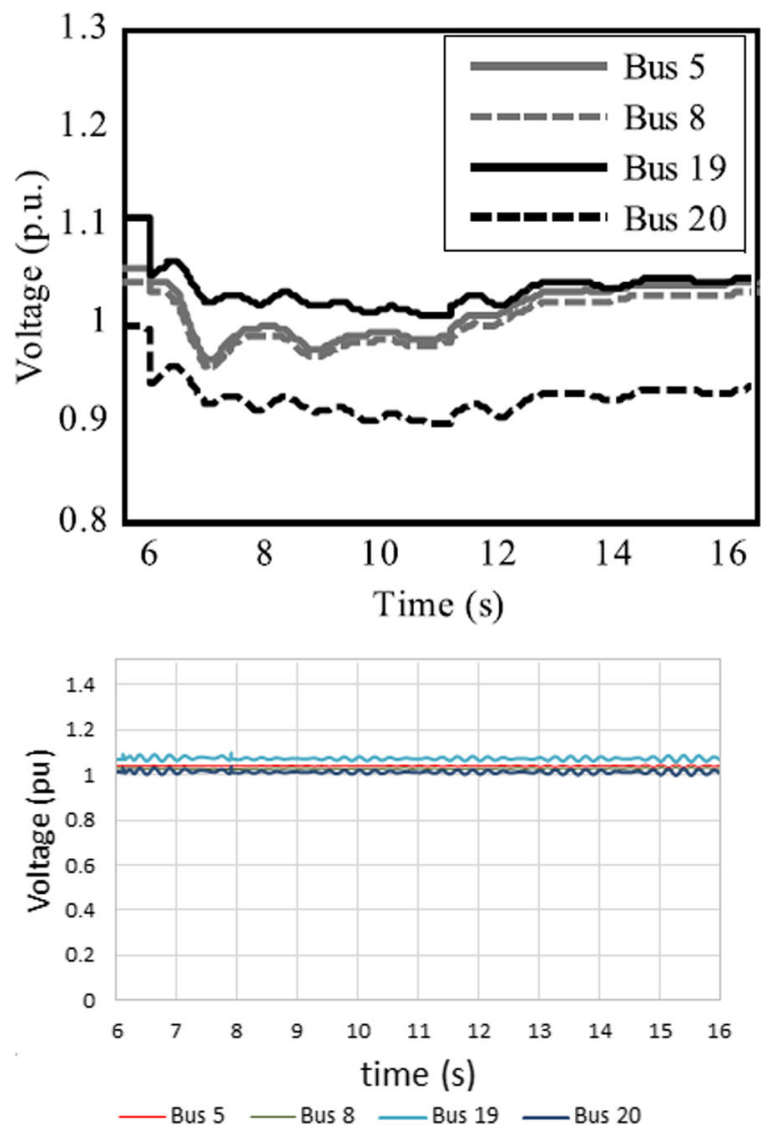

Fig. 22 VSRI(a) and VSI(b) based load shedding
Integrity Protection System (SIPS) to initiate remedial actions. These actions are usually pre-planned, aid to alleviate the consequences and keep system parameters within limits. SIPS actions comprise of generation or load shedding or system configuration changes to maintain system stability. Thus, the study attempts to contribute towards dynamic stability assessment for selfhealing of smart grid using the pioneering technology of synchrophasor based wide area monitoring protection and control. A special protection scheme for voltage stability monitoring using synchrophasors from microPMU, based on recent incidents of instability and lack of reliability in power supply in a proposed smart city, is presented.

The novel idea is of introducing cutting-edge microPMU applications for enhancing distribution grid operation efficiency in the march towards smart city vision. The capability of initiating the SPS scheme based on local monitoring along with accuracy and fast response of $\mu$ PMU measurements are added advantages of proposed scheme. While deriving the VSI from local phasors, the effect of both local network as well as power system outside the considered node is taken into account by formulating an equivalent source and impedance model. The load participation factors arrived using modal analysis of the system helps in most appropriate load curtailment strategy. The future scope of work lies in field implementation of the scheme and extending it to other real-world complex power system networks containing various type of renewable energy sources. The future research objective envisages a closed loop control scheme, which can act based on inputs as well as monitor the effects of actions based on feedback.

\section{Acknowledgments}

The paper is as part of a research work on "Power System Voltage Stability Analysis using synchrophasors in Distribution System of Kerala Grid" at Kerala State Electricity Board Ltd., the only state-owned integral utility in power sector of Kerala state in India.

\section{Authors' contributions}

An intelligent amalgam of smart protection system with cutting edge synchrophasor technology is used for deriving a decision support scheme for distribution automation, in this study. The special protection scheme derived by DSK and JSS utilizes synchrophasor data from local micro-Phasor Measurement Unit planned to be placed at one of the key nodes of the distribution system network in the city of Thiruvananthapuram, a proposed smart city and the capital city of Kerala state. The real time data SCADA data collected by BSS is utilised to derive a novel voltage stability index solely based on local data which helps in initiating the SPS. Thus the scheme has practical application in the power sector of Kerala. All authors read and approved the final manuscript.

\section{Funding}

Not Applicable

Availability of data and materials Not Applicable

\section{Competing interests}

The authors declare that they have no competing interests. 


\section{Author details}

${ }^{1}$ Dept of Electrical Engineering, College of Engineering, Trivandrum, Kerala, India. ${ }^{2} 400 / 220 k V$ Substation, Powergrid Corporation of India Ltd., Trivandrum, Kerala, India. ${ }^{3}$ Power System Operations, Kerala State Electricity Board Ltd. Kerala, India.

Received: 26 March 2019 Accepted: 9 October 2019

Published online: 24 February 2020

\section{References}

1. Wu, Z., Du, X., Gu, W., Ling, P., Liu, J., Fang, C. (2018). Optimal Micro-PMU Placement Using Mutual Information Theory in Distribution Networks. Energies, 11(7), 1917. https://doi.org/10.3390\%2Fen11071917.

2. Soonee, S.K., Agrawal, V.K., Agarwal, P.K., Narasimhan, S.R., Thomas, M.S (2015). The View from the Wide Side: Wide-Area Monitoring Systems in India. IEEE Power and Energy Magazine, 13(5), 49-59. https://doi.org/10. 1109\%2Fmpe.2015.2431216.

3. Pandey, R.K., Pentayya, P., Gartia, A., Rajkumar, A., Kumar, C. (2013). Operational reliability enhancement with PMUs in Indian power network, In 2013 IEEE 1st International Conference on Condition Assessment Techniques in Electrical Systems (CATCON). https://doi.org/10.1109\%2Fcatcon.2013.6737465: IEEE.

4. Phadke, A.G. (1993). Synchronized phasor measurements in power systems. IEEE Computer Applications in Power, 6(2), 10-15. https://doi.org/10. $1109 \% 2 F 67.207465$.

5. Pandey, R.K., Archana, S.M., Nayyar, K., Pentayya, P., Kumar, C. (2014). PMU signal prioritization for effective control coordination of load despatch centres, In 2014 IEEE PES General Meeting | Conference \& Exposition. https:// doi.org/10.1109\%2Fpesgm.2014.6939069: IEEE.

6. Phadke, A.G., \& Thorp, J.S. (2017). Synchronized Phasor Measurements and Their Applications: Springer International Publishing. https://doi.org/10. 1007\%2F978-3-319-50584-8.

7. Wache, M., \& Murray, D.C. (2011). Application of Synchrophasor Measurements for distribution networks, In 2011 IEEE Power and Energy Society General Meeting. https://doi.org/10.1109\%2Fpes.2011.6039337: IEEE.

8. Ding, F., \& Booth, C.D. (2012). Protection and stability assessment in future distribution networks using PMUs, In 11th IET International Conference on Developments in Power Systems Protection (DPSP 2012). https://doi.org/10. 1049\%2Fcp.2012.0094: IET.

9. Schweitzer, E.O., Whitehead, D., Zweigle, G., Ravikumar, K.G. (2010). Synchrophasor-based power system protection and control applications, In 2010 63rd Annual Conference for Protective Relay Engineers. https://doi. org/10.1109\%2Fcpre.2010.5469481: IEEE.

10. Schweitzer, E.O. (2009). Whitehead DE. Real-world synchrophasor solutions, In 2009 62nd Annual Conference for Protective Relay Engineers. https:// doi.org/10.1109\%2Fcpre.2009.4982540: IEEE.

11. Skok, S., Ivankovic, I., Cerina, Z. (2007). Applications Based on PMU Technology for Improved Power System Utilization, In 2007 IEEE Power Engineering Society General Meeting. https://doi.org/10.1109\%2Fpes.2007.385580: IEEE.

12. Chenine, M., Vanfretti, L., Bengtsson, S., Nordstroum, L. (2011). Implementation of an experimental wide-area monitoring platform for development of synchronized phasor measurement applications, In 2011 IEEE Power and Energy Society General Meeting. https://doi.org/10.1109\%2Fpes.2011. 6039672: IEEE.

13. Rihan, M., Ahmad, M., Beg, M.S. (2011). Phasor measurement units in the Indian smart grid, In ISGT2011-India. https://doi.org/10.1109\%2Fiset-india. 2011.6145392: IEEE.

14. von Meier, A., Culler, D., McEachern, A., Arghandeh, R. (2014). Microsynchrophasors for distribution systems, In ISGT 2014. https://doi.org/10. 1109\%2Fisgt.2014.6816509: IEEE.

15. Mohsenian-Rad, H., Stewart, E., Cortez, E. (2018). Distribution Synchrophasors: Pairing Big Data with Analytics to Create Actionable Information. IEEE Power and Energy Magazine, 16(3), 26-34. https://doi.org/10.1109\%2Fmpe. 2018.2790818.

16. von Meier, A., Stewart, E., McEachern, A., Andersen, M., Mehrmanesh, L. (2017). Precision Micro-Synchrophasors for Distribution Systems: A Summary of Applications. IEEE Transactions on Smart Grid, 8(6), 2926-2936. https://doi.org/10.1109\%2Ftsg.2017.2720543.

17. Liao, A.L., Stewart, E.M., Kara, E.C. (2016). Micro-synchrophasor data for diagnosis of transmission and distribution level events, In 2016 IEEE/PES
Transmission and Distribution Conference and Exposition (T\&D). https://doi. org/10.1109\%2Ftdc.2016.7519975: IEEE.

18. von Meier, A., Arghandeh, R., et al. (2014). Diagnostic applications for microsynchrophasor measurements. Berkeley: California Institute for Energy and Environment.

19. Sanchez-Ayala, G., Aguerc, J.R., Elizondo, D., Lelic, M. (2013). Current trends on applications of PMUs in distribution systems, In 2013 IEEE PES Innovative Smart Grid Technologies Conference (ISGT). https://doi.org/10.1109\%2Fisgt. 2013.6497923: IEEE.

20. Shahsavari, A., Farajollahi, M., Stewart, E., Roberts, C., Megala, F., Alvarez, L., et al. (2017). Autopsy on active distribution networks: A data-driven fault analysis using micro-PMU data, In 2017 North American Power Symposium (NAPS). https://doi.org/10.1109\%2Fnaps.2017.8107265: IEEE.

21. Fang, X., Misra, S., Xue, G., Yang, D. (2012). Smart Grid - The New and Improved Power Grid: A Survey. IEEE Communications Surveys \& Tutorials, 14(4), 944-980. https://doi.org/10.1109\%2Fsurv.2011.101911.00087.

22. Zheng, C., \& Kezunovic, M. (2010). Distribution system voltage stability analysis with wind farms integration, In North American Power Symposium 2010. https://doi.org/10.1109\%2Fnaps.2010.5618978: IEEE.

23. Azmy, A.M., \& Erlich, I. (2005). Impact of distributed generation on the stability of electrical power systems, In IEEE Power Engineering Society General Meeting. https://doi.org/10.1109\%2Fpes.2005.1489354: IEEE.

24. Ajjarapu, V., \& Lee, B. (1998). Bibliography on voltage stability. IEEE Transactions on Power Systems, 13(1), 115-125. https://doi.org/10.1109\%2F59. 651622.

25. Cutsem, T., \&Vournas, C. (1998). Voltage Stability of Electric Power Systems. https://doi.org/10.1007\%2F978-0-387-75536-6.

26. Vournas, C. (2015). Power System Voltage Stability, In Encyclopedia of Systems and Control. https://doi.org/10.1007\%2F978-1-4471-5058-9_263 (pp. 1085-1090). London: Springer.

27. Otomega, B., \& Cutsem, T.V. (2007). Undervoltage Load Shedding Using Distributed Controllers. IEEE Transactions on Power Systems, 22(4), 18981907. https://doi.org/10.1109\%2Ftpwrs.2007.907354.

28. Glavic, M., \& Cutsem, T.V. (2009). Wide-Area Detection of Voltage Instability From Synchronized Phasor Measurements. Part I: Principle. IEEE Transactions on Power Systems, 24(3), 1408-1416. https://doi.org/10.1109 \%2Ftpwrs.2009.2023271.

29. Jiang, H., Zhang, Y., Zhang, J.J., Gao, D.W., Muljadi, E. (2015). SynchrophasorBased Auxiliary Controller to Enhance the Voltage Stability of a Distribution System With High Renewable Energy Penetration. IEEE Transactions on Smart Grid, 6(4), 2107-2115. https://doi.org/10.1109\%2Ftsg.2014.2387012.

30. Kumar, D.S., \& Savier, J.S. (2018). Synchrophasor Based System Integrity Protection Scheme for Voltage Stability in Northern Kerala, In 2018 IEEE Innovative Smart Grid Technologies - Asia (ISGT Asia). https://doi.org/10.1109 \%2Fisgt-asia.2018.8467978: IEEE.

31. Kundur, P. (2007). Power System Stability, In Power System Stability and Control. https://doi.org/10.1201\%2F9781420009248.sec2: CRC Press.

32. Arief, A., Nappu, M.B., Yin, X., Zhou, X., Dong, Z.Y. (2009). Under voltage load shedding design with modal analysis approach, In 8th International Conference on Advances in Power System Control, Operation and Management (APSCOM 2009). https://doi.org/10.1049\%2Fcp.2009.1822: IET.

33. Arief, A., Nappu, M.B., Dong, Z.Y., Arief, M. (2010). Under voltage load shedding incorporating bus participation factor. https://doi.org/10.1109 \%2Fipecon.2010.5697058

34. Subramani, C., Dash, S.S., Bhaskar, M.A., Jagadeeshkumar, M., Sureshkumar, K., Parthipan, R. (2009). Line outage contingency screening and ranking for voltage stability assessment, In 2009 International Conference on Power Systems. https://doi.org/10.1109\%2Ficpws.2009.5442743: IEEE.

35. Yazdanpanah-Goharrizi, A., \& Asghari, R. (2007). A novel line stability index (NLSI) for voltage stability assessment of power systems, In Proceedings 7th WSEAS Int. Conf. on Power Systems (pp. 164-167).

36. Kanimozhi, R., \& Selvi, K. (2013). A Novel Line Stability Index for Voltage Stability Analysis and Contingency Ranking in Power System Using Fuzzy Based Load Flow. Journal of Electrical Engineering and Technology, 8(4), 694-703. https://doi.org/10.5370\%2Fjeet.2013.8.4.694.

37. Althowibi, F.A., \& Mustafa, M.W. (2010). Line voltage stability calculations in power systems, In 2010 IEEE International Conference on Power and Energy. https://doi.org/10.1109\%2Fpecon.2010.5697616: IEEE.

38. Deng, P., Sun, Y., Xu, J. (2009). A New Index of Voltage Stability Considering Distribution Network, In 2009 Asia-Pacific Power and Energy Engineering Conference. https://doi.org/10.1109\%2Fappeec.2009.4918070: IEEE. 
39. Wang, Y., Li, W., Lu, J. (2009). A new node voltage stability index based on local voltage phasors. Electric Power Systems Research, 79(1), 265-271. https://doi.org/10.1016\%2Fj.epsr.2008.06.010.

40. Chattopadhyay, T.K., Banerjee, S., Chanda, C.K. (2014). Impact of distributed generator on voltage stability analysis of distribution networks under critical loading conditions for composite loads, In International Conference on Electronics, Communication and Instrumentation (ICECI). https://doi.org/10. 1109\%2Ficeci.2014.6767367: IEEE.

41. Pérez-Londoño, S., Rodríguez, L.F., Olivar, G. (2014). A Simplified Voltage Stability Index (SVSI). International Journal of Electrical Power \& Energy Systems, 63, 806-813. https://doi.org/10.1016\%2Fj.ijepes.2014.06.044.

42. Seethalekshmi, K., Singh, S.N., Srivastava, S.C. (2010). Adaptive Scheme for Minimal Load Shedding Utilizing Synchrophasor Measurements to Ensure Frequency and Voltage Stability. Electric Power Components and Systems, 38(11), 1211-1227. https://doi.org/10.1080\%2F15325001003652884.

43. Pai, M.A. (1989). Energy Function Analysis for Power System Stability: Springer US. https://icseg.iti.illinois.edu/ieee-39-bus-system/.

\section{Submit your manuscript to a SpringerOpen ${ }^{\circ}$ journal and benefit from:}

- Convenient online submission

- Rigorous peer review

- Open access: articles freely available online

- High visibility within the field

- Retaining the copyright to your article

Submit your next manuscript at $>$ springeropen.com 